\title{
Internet of Things for Smart Cities: Current Issues and Research Challenges
}

\author{
Omnia Saidani Neffati, Oumaima Saidani, Devi Mani, Pooja Dixikha G.
}

\begin{abstract}
Every day, we are stepping towards to lead a smart life within a smart world, thanks of IoT smart applications. The continually need for new urban systems including smart infrastructures, smart energy grids and smart mobility systems makes appear of a new concept, named: "Smart City". This concept represents one of the most promising challenges of IoT applications since it involves the enhancement of our lifestyle. Among its promising advantage we can cites: the reducing resource consumption, the real-time guidance for citizens, the transportation facilities, etc. In this paper, we propose, first, a literature review on researches addressing many aspects of Smart City. Second, we provide a comparative study between these researches on the basic of multiple criteria like interoperability, scalability, security, etc.
\end{abstract}

Keywords: Internet of Things (IoT), Smart Cities, Urban Systems, Sensor, Security, Interoperability, Scalability, Privacy, Context-awareness, Cloud Computing, Big Data, Ontology.

\section{INTRODUCTION}

$\mathrm{N}$ owadays, Internet becomes an indispensable concept in our life. Its presence in all our life aspects makes it, actually,

Eventually, communication and interaction in the Internet has developed from "user -to-user" towards "device-todevice". In fact, we are not talking, now, about interaction, just, between people, but also, about interaction between people and physical objects and moreover between physical objects and other physical objects, too.

This evolution lead us to talk about a relatively new concept that have been proposed, the first time, by Kevin Ashton [1] in 1999 and which makes "things" or "objects" interconnected with each other's over the Internet. This concept is defined by the term of "Internet of Things" (IoT).

Revised Manuscript Received on February 15, 2020.

* Correspondence Author

Omnia Saidani Neffati*, Department of Computer Science, College of Science and Arts of Sarat Abida, King Khalid University, Abha, KSA. Email: oneffati@kku.edu.sa

Oumaima Saidani, Department of Information Systems, Princess Nourah bint Abdulrahman University, College of Computer and Information Sciences, Riyadh, Kingdom of Saudi Arabia. Email: OCSaidani@pnu.edu.sa

Devi Mani, Department of Computer Science, College of Science and Arts of Sarat Abida, King Khalid University, Abha, KSA. Email : devinov6@gmail.com

Pooja Dixikha G., Department of Electronics \& Communication Engineering, Sona College of Technology, Salem Tamil Nadu , India. - 636 005Email: dhurkha.g@gmail.com

(C) The Authors. Published by Blue Eyes Intelligence Engineering and Sciences Publication (BEIESP). This is an open access article under the CC BY-NC-ND license (http://creativecommons.org/licenses/by-nc-nd/4.0/) an inevitable tool.

Things include humans, smart phones, vehicles, industrial equipments, clothing, landmarks, monuments, etc. These things are acting as sensors that are able to interact with each other to achieve a well defined goal. Thanks to IoT concept, people become able to communicate, control and act their environment.

IoT platform makes our devices smarter, our processing as an intelligent, and our communication as an informative. The exciting features of IoT allow it to take advantage of a great spread into our life. In fact, domains that are concerned by IoT are too impressive: home, city, enterprise, agriculture, health, industry, education, entertainment, etc.

In this paper, we provide a literature review on Smart Cities approaches. This survey aims; (i) first, at exploring the exiting opportunities offered by existing Smart Cities approaches, their strengths as well as their limitations., (ii) second, at providing a comparative study between these approaches on the basic of multiple criteria such as security, scalability, privacy, context management, used techniques, etc.

The remainder of this paper is organized as follows: Section 2 introduces the research questions as well as the research methodology followed in this research. Section 3 introduces a background. Section 4 presents overview of the retained Smart Cities approaches. Section 5 provides a comparison between these approaches and discussion about the main observations. Finally, section 6 present the conclusion and future work.

\section{RESEARCCH QUESTIONS AND METHODOLOGY}

\section{A. Research questions}

The goal of this paper is to emphasize the opportunities offered by the relevant existing approaches for Smart Cities as well as their limitations. Thereafter, we propose taxonomy of these approaches.

More precisely, we seek answers to the three following research questions:

Research Question 1: Which are the current challenging issues raised by Smart Cities approaches?

Research Question 2: Which are the solutions proposed regarding the raised issues?

Research Question 3: Which are the main underlined limitations of Smart Cities approaches?

\section{B. Research methodology}

In this research, we have analyzed eight pertinent existing approaches concerned by the Smart Cities paradigm. 
This research is performed by using different libraries which are mainly:

- ACM Digital Library

- IEEE Xplore

- Springer Link

- Science Direct

Throughout our research process, we run, essentially, five queries using the Google Scholar web search engine. The five search queries are the following:

1) Q1:"IoT"+"Smart City"+"approach"

2) Q2:"IoT"+Smart City"+"architecture"

3) Q3:"IoT"+Smart City"+"platform"

4) Q4:"IoT"+Smart City"+"model"

5) Q5:'IoT"+Smart City"+"'experimentation"

A filtering processing, afterwards, is applied on the found researches by: first, reading titles and abstracts and second, by the application of the four following selection criteria:

- The research publication year should be from 2014, in order to guarantee the novelty of the research.

- The research should be implemented in a prototype (i.e. not limited to theoretical considerations).

- The research should be well cited by other researches.

- The research should be written in English.

Table-I presents the eight retained approaches, their publication year, their types (journal, conference, workshop) their source library and finally their number of citations (according to Google Scholar).

Fig. 1 and Fig. 2 show the distribution of the retained approaches according to their type and their source library.

Table-I. Classification of the retained approaches by: year, type, source library and number of citations.

\begin{tabular}{|c|c|c|c|c|}
\hline Approach & $\begin{array}{c}\text { Publication } \\
\text { year }\end{array}$ & Type & $\begin{array}{c}\text { Source } \\
\text { library }\end{array}$ & $\begin{array}{c}\text { Number } \\
\text { of } \\
\text { citation } \\
\text { s }\end{array}$ \\
\hline Cheng et al., & 2018 & Journal & IEEE & 65 \\
\hline Teng et al., & 2019 & Journal & $\begin{array}{c}\text { Science } \\
\text { Direct }\end{array}$ & 48 \\
\hline $\begin{array}{c}\text { Rathore et } \\
\text { al., }\end{array}$ & 2016 & Journal & $\begin{array}{c}\text { Science } \\
\text { Direct }\end{array}$ & 392 \\
\hline $\begin{array}{c}\text { Krylovskiy } \\
\text { et al., }\end{array}$ & 2016 & Conference & IEEE & 154 \\
\hline $\begin{array}{c}\text { Lea and } \\
\text { Blackstock., }\end{array}$ & 2014 & Workshop & ACM & 44 \\
\hline Bonino et al., & 2015 & Conference & IEEE & 69 \\
\hline $\begin{array}{c}\text { Paganelli et } \\
\text { al., }\end{array}$ & 2014 & Journal & IEEE & 63 \\
\hline Khan et al., & 2014 & Journal & Springer & 47 \\
\hline
\end{tabular}

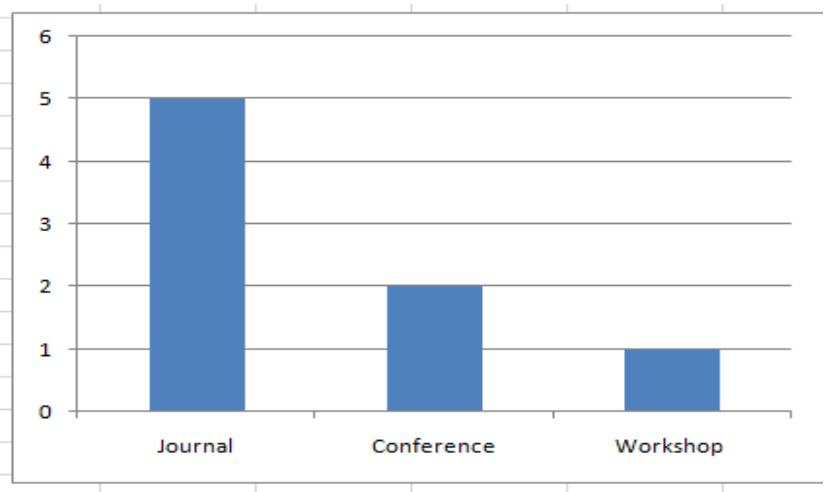

Fig. 1.Distribution of retained approaches by type of publication.
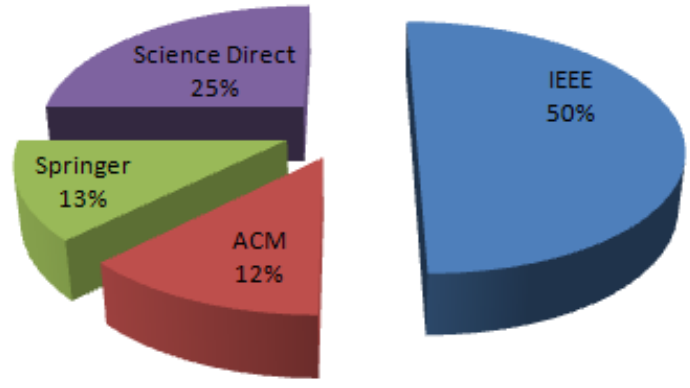

Fig. 2.Distribution of retained approaches by source library.

\section{BACKGROUND}

\section{A. Internet of Things (IoT)}

Internet of Things (IoT) can be defined as a "world-wide network of interconnected objects uniquely addressable, based on standard communication protocols" [2].

According to [3], things have identities and virtual personalities operating in smart spaces using intelligent interfaces to connect and communicate within social, environmental, and user contexts.

They are seen as active participants in business, information and social processes where they are enabled to interact and communicate among themselves and with the environment Cluster of European research projects on the Internet of Things [4]. This communication is ensured by exchanging information sensed about the environment.

\section{B. Smart city}

According to [5], the term "smart" refers to the ability to automatically obtain and apply knowledge. The city can be determined as smart if it is fully equipped with information and communication technologies and rendering e-services to population [6]. The main purpose of a "Smart City" is to provide a new approach to urban management in which all aspects are handled considering the interconnection that takes place in the real life of the city [7].

\section{Sensor and Wireless Sensor Networks}

Sensors allow converting raw physical data into digital signals and transmitting them to its control center. Through sensors, we can monitor environmental changes remotely from any part of the world via internet [8].

A wireless sensor network is a collection of large number of sensor nodes and at least one base station. The sensor node is a device consisting, essentially, of four units that are sensing, processing, communication and power supply [9].

\section{RETAINED APPROACHES}

In this section we will present the eight retained Smart Cities approaches.

Published By:

Blue Eyes Intelligence Engineering 


\section{A. Lea and Blackstock [10]}

In this research, the authors propose to apply the paradigm of IoT on a hub-centric approach to establish smart cities. Besides, the authors present experimentation on two projects in Canada and UK.

The authors consider, beneficial, the usage of hubs as an architecture for IoT since hubs provide, on the one hand, an easy-to-use interface for emerging IoT infrastructure of the city, and on the other hand, because they offer an efficient interoperability point through a common hub API (Application Programming Interface) allowing developers to access multiple hubs where each one is considered as a subgroup of the smart city infrastructure.

According to the authors, the main challenge faced during working in the two projects is to find a uniform API in order to collect and manage the heterogeneous sets of data sources. In fact, data sources are different since they can be from real-time data or from, relatively, static data.

In order to solve this problem, the authors propose the building of two different hubs. The first one, named WoTKit, presents a web-centric IoT toolkit, focused on managing things that exhibit real-time behavior while the second, named CKAN, focused on storing static data.

\section{B. Bonino et al., approach[11]}

In this research, the authors introduce a smart city supported platform. The main platform objective consists on offering smart services to the citizens. It allows, moreover, integrating services that provide the enhancement of data and information. Its design (validated by experimentation) shows its ability to collect and analyze data, from heteregenous sources.

\section{Khan et al., approach[12]}

The main challenge raised in this research is that citizens are facing to the formulation of coherent information from the huge volumes of data available to them. So, the need to be facilitated with the right contextual information about the characteristics of their urban environment remains necessary, and this is in order to contribute to the aspects of urban governance affecting them.

The authors underline, also, the challenge related to the integration of data from mixed sources. This challenge involves the collection of large volume of data and their analysis in order to deduce useful information. Harmonization of these data, standardization of their formats as well as the establishment of the necessary mechanisms to fulfill contextual relevance of data with its consumers, remain so required.

\section{Krylovskiy et al., approach [13]}

In this research, the authors confirm that IoT is an enabler key for building large-scale smart city. However, creation of platforms that take into account cross-domain applications remains a significant challenge.

Facing this challenge, a service-based project, called, DIMMER Smart City Project is proposed. This project uses "micro-service" architectural style in order to create a smart city IoT framework that is able to cover diverse applications.

According to the authors, the adoption of micro-service architectural style for creating large-scale smart city is beneficial, mainly, in terms of (i) the support of technology heterogeneity, (ii) resilience, (iii) organizational alignment and (iv) Composability.

\section{E. Paganelli et al., approach [14]}

In this work, the authors propose a Web of Thing (WoT) framework for turning smart things.

According to the authors, REST is a well acceptable architectural style for the Web that is beneficial in terms of simplicity, interoperability and scalability.

The authors have evaluated user acceptance and $40 \%$ have considered this application is intuitive and easy to use.

\section{F. Rathore et al., approach[15]}

In this research, the authors propose a Big Data analytics-based architecture for smart city

The main goal of the proposed 4-tier architecture is to analyze the huge volume of data coming from different sources.

In order to materialize the proposed architecture, the authors have developed a system that is made of two major modules, namely "smart city implementation" and "urban planning implementation".

The "Urban planning implementation» consists of three different levels; the physical level that stores all the historical data, the intermediate level that performs, essentially, statistical calculation and graph analysis, and the upper level that make decision regarding the urban planning.

\section{G. Cheng et al., approach [16]}

In this research paper, the authors propose a standard-based approach for the design and the implementation of a new fog computing-based framework (FogFlow).

According to the authors, the proposed framework can solve problems related, especially, to the dynamic configuration and management of data processing tasks, optimization of task allocation, openness and interoperability.

The definitions of the specification method of service topology as well as the method of operators' implementation are ensured through declarative hints. Two types of hints are distinguished: "granularity hint" and "stream shuffling hint". The framework contains also, the context management.

\section{H. Teng et al., approach [17]}

In this research paper, the authors propose a new low-cost code dissemination scheme. In fact, according to the authors, realizing smart city requires a big number of smart sensors.

The VCMCD scheme proposed by the authors uses the mobile vehicles (Code Mules) to ensure the transmission of the update code from the "Code Stations" to smart sensors with low cost. "Code Stations" Code are devices responsible for getting the update code from the Internet. Their essential functions are getting the update code from code station, on the one hand, and transmitting the update code to the update sensor.

\section{COMPARISON CRITERIA}

In this section, we provide comparison study between the approaches already presented in section 4. This comparison is based on multiple criteria that we have devised into two categories:

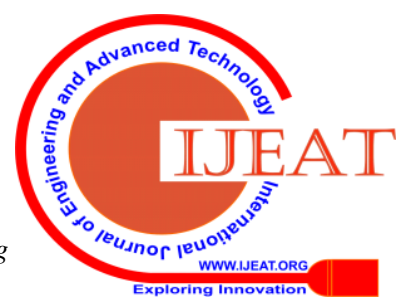


1) Category 1: that covers criteria that we think, generally, useful to identify; the objective of the approach, the challenge that it raises, its specific characteristics and the techniques that it uses. This first category contains the three following criteria:

\section{- Criterion 1: Challenge}

This criterion is about the challenge raised by the approach.

- Criterion 2: Focus

This criterion identify on which the approach focuses essentially: on user, on data processing, etc.

- Criterion 3: particular concept/technology

This criterion allows identifying any particular concept or technology used by the approach to establish Smart City.

2) Category 2: that covers the required IoT applications/platforms characteristics.

This second category contains the following criteria:

\section{- Criterion 4: Interoperability}

This criterion determines if interoperability is supported by the approach or not. Interoperability means the ability of communication and interactions between different devices, protocols, systems, etc.

\section{- Criterion 5: Scalability}

This criterion determines if the approach is scalable or not. Scalability means the ability of a system to manage a large amount of work.

\section{- Criterion 6: Security}

This criterion allows to identify if security is supported by the approach or not by using some security policies and protocols, for example.

\section{- Criterion 7: Privacy}

This criterion identifies if the retained approach take into consideration users' privacy or not. Privacy can be defined individual's right to not be observed or disturbed.

\section{- Criterion 8: Power consumption}

This criterion determines if power consumption issue is taken into consideration by the retained approach and if it gives techniques aiming at power consumption or not.

\section{- Criterion 9: Recoverability}

This criterion allows to indicate if the retained approach offers mechanisms/techniques to restore, replace, or fix objects (e.g. services, sensors) that may stop working due to unexpected faults and get the architecture to a state in which it can perform expected functionality [18].

\section{- Criterion 10: Availability}

This criterion indicates if the retained approach provides mechanisms/techniques in order to ensure, continually, the storage, process, data and services to users.

\section{- Criterion 11: Cost management}

This criterion indicates if the retained approach takes into account the cost management issue or not by providing some techniques/mechanisms allowing to reduce the cost related to sensors and various types of smart objects implementation and communication.

\section{- Criterion 12: Context-management}

This criterion determine if the approach allows to handle with the context or doesn't. That's to say, if the approach manages context data and associate actions for specific circumstances and environments, or doesn't.

\section{RESULT ANALYSIS}

Table -II shows the positioning of the retained approaches regarding the presented criteria.

In Rathore et al., approach, interoperability is well taken into consideration in this research, as well as the security through the Security management module included in the "Smart city implementation" module. However, scalability, context management, privacy, power consumption, recoverability, availability, cost management and context management are not. The strong point in the Rathore et al., approach is the providing of a deep and efficient processing and analysis of data with massive volume. This research is, fully, data-centric and this is shown through the introduction of all small details concerned with the manner of data collect, processing, analysis, management, etc.

The Krylovskiy et al., approach is data-centric since it focuses on managing of different formats of data coming from different sources. Interoperability and scalability are taken into account by this approach because of systems that have been built with micro-service architecture are, typically, associated with the technology heterogeneity, scalability and composability advantages. Context management is supported, also, by this approach. In fact, this approach provides a "Context Awareness Framework" ensuring context awareness features to the applications. However, security, privacy, power consumption, recoverability, availability and cost management are not supported in this approach. The Lea and Blackstock approach is data-centric since it focuses, principally, on handling with the heterogeneous types and sources of data. Interoperability and security are ensured in this approach. However, scalability as well as the context management, privacy, power consumption, recoverability, availability, cost management and context management are not taken into account by this approach. The Bonino et al,. approach, is data-centric Interoperability and scalability are supported by this approach. Security, also, is taken into account. However, privacy, power consumption, recoverability, availability, cost management and context management are not taken into consideration by this approach. The Paganelli et al., approach is both web-centric and user-centric. Interoperability and scalability are supported in this approach. However, security, privacy, power consumption, recoverability, availability, cost management and context-management are not taken into consideration.The Khan et al., approach takes into account interoperability, scalability, security and context management. However recoverability, availability and cost management are not supported. In Cheng et al., approach, interoperability, scalability and availability are well supported. However, security, privacy, context management, power consumption and recoverability are not. In Teng et al., approach, only interoperability is taken into account since communication and interactions between different devices and protocols is ensured. 
Table- II: The positioning of the retained approaches regarding the presented criteria

\begin{tabular}{|c|c|c|c|c|c|c|c|c|c|c|c|c|}
\hline Criterion & Challenge & Focus & $\begin{array}{c}\text { Particular } \\
\text { concept/ } \\
\text { technolog } \\
y\end{array}$ & $\begin{array}{l}\text { Interope } \\
\text { rability }\end{array}$ & $\begin{array}{c}\text { Scalabili } \\
\text { ty }\end{array}$ & $\begin{array}{c}\text { Securit } \\
y\end{array}$ & Privacy & $\begin{array}{c}\text { Power } \\
\text { consump } \\
\text { tion }\end{array}$ & $\begin{array}{l}\text { Recover } \\
\text { ability }\end{array}$ & $\begin{array}{c}\text { Availabil } \\
\text { ity }\end{array}$ & $\begin{array}{c}\text { Cost } \\
\text { manag } \\
\text { ement }\end{array}$ & $\begin{array}{c}\text { Contex } \\
t \\
\text { manag } \\
\text { ement }\end{array}$ \\
\hline $\begin{array}{l}\text { Cheng et } \\
\text { al., }\end{array}$ & $\begin{array}{l}\text {-Configuration } \\
\text { and management } \\
\text { of data } \\
\text { processing tasks } \\
\text { dynamically. } \\
\text {-Ensuring } \\
\text { openness and } \\
\text { interoprability. }\end{array}$ & $\begin{array}{c}\text { Data-ce } \\
\text { ntric }\end{array}$ & $\begin{array}{l}\text { Edge } \\
\text { Cloud }\end{array}$ & $\checkmark$ & $\checkmark$ & $x$ & $x$ & $x$ & $x$ & $\checkmark$ & $x$ & $\checkmark$ \\
\hline Teng et al., & $\begin{array}{l}\text {-Disseminating } \\
\text { the update code } \\
\text { to the smart } \\
\text { sensors. }\end{array}$ & $\begin{array}{c}\text { Data-ce } \\
\text { ntric }\end{array}$ & $\begin{array}{c}\text { Cloud } \\
\text { computing }\end{array}$ & $\checkmark$ & $x$ & $x$ & $x$ & $x$ & $x$ & $x$ & $x$ & $x$ \\
\hline $\begin{array}{l}\text { Rathore et } \\
\text { al., }\end{array}$ & $\begin{array}{l}\text {-Processing and } \\
\text { analysis of } \\
\text { massive } \\
\text { volume of data. } \\
\text {-Harmonization } \\
\text { and managing of } \\
\text { heterogeneous } \\
\text { data. }\end{array}$ & $\begin{array}{c}\text { Data-ce } \\
\text { ntric }\end{array}$ & $\begin{array}{l}\text { Big Data } \\
\text { (Hadoop } \\
\text { framework } \\
+ \text { SPark) }\end{array}$ & $\checkmark$ & $x$ & $\checkmark$ & $x$ & $x$ & $x$ & $x$ & $x$ & $\times$ \\
\hline $\begin{array}{l}\text { Krylovskiy } \\
\text { et al., }\end{array}$ & $\begin{array}{l}\text {-Harmonization } \\
\text { and managing of } \\
\text { heterogeneous } \\
\text { data. }\end{array}$ & $\begin{array}{l}\text { Data-ce } \\
\text { ntric }\end{array}$ & $\begin{array}{l}\text { Micro-serv } \\
\text { ice }\end{array}$ & $\checkmark$ & $\checkmark$ & $x$ & $x$ & $\mathrm{x}$ & $x$ & $x$ & $x$ & $\checkmark$ \\
\hline $\begin{array}{c}\text { Lea and } \\
\text { Blackstock. } \\
\text {, }\end{array}$ & $\begin{array}{l}\text {-Harmonization } \\
\text { and managing of } \\
\text { heterogeneous } \\
\text { data. }\end{array}$ & $\begin{array}{c}\text { Data-ce } \\
\text { ntric }\end{array}$ & Hub & $\checkmark$ & $x$ & $\checkmark$ & $x$ & $\bar{x}$ & $\bar{x}$ & $x$ & $x$ & $x$ \\
\hline $\begin{array}{l}\text { Bonino et } \\
\text { al., }\end{array}$ & $\begin{array}{l}\text {-Harmonization } \\
\text { and managing of } \\
\text { heterogeneous } \\
\text { data. }\end{array}$ & $\begin{array}{c}\text { Data-ce } \\
\text { ntric }\end{array}$ & Ontology & $\checkmark$ & $\checkmark$ & $\checkmark$ & $\bar{x}$ & $x$ & $\bar{x}$ & $x$ & $x$ & $x$ \\
\hline $\begin{array}{l}\text { Paganelli et } \\
\text { al., }\end{array}$ & $\begin{array}{l}\text {-Modeling and } \\
\text { turning smart } \\
\text { things into } \\
\text { web-addressable } \\
\text { resources. } \\
\text {-Provision of } \\
\text { tools supporting } \\
\text { users in } \\
\text { composing, } \\
\text { publishing, and } \\
\text { sharing the web } \\
\text { representation of } \\
\text { smart devices. }\end{array}$ & $\begin{array}{l}\text { Web-ce } \\
\text { ntric } \\
\text { user-cen } \\
\text { tric }\end{array}$ & $\begin{array}{c}\text { REST } \\
\text { (Represent } \\
\text { ational } \\
\text { State } \\
\text { Transfer) }\end{array}$ & $\checkmark$ & $\checkmark$ & $x$ & $\checkmark$ & $x$ & $\bar{x}$ & $x$ & $x$ & $x$ \\
\hline Khan et al., & $\begin{array}{l}\text {-Harmonization } \\
\text { and managing of } \\
\text { heterogeneous } \\
\text { data. } \\
\text {-Providing the } \\
\text { right contextual } \\
\text { information }\end{array}$ & $\begin{array}{l}\text { Data-ce } \\
\text { ntric } \\
\text { User-ce } \\
\text { ntric }\end{array}$ & $\begin{array}{l}\text { Cloud } \\
\text { computing }\end{array}$ & $\checkmark$ & $\checkmark$ & $\checkmark$ & $\checkmark$ & $\checkmark$ & $\bar{x}$ & $x$ & $x$ & \\
\hline
\end{tabular}

Three essential observations are recorded throughout the analysis of the presented approaches: First, the main challenge raised by the presented approaches concerns the harmonization and the management of heterogeneous data coming from different sources. The concerned approaches have provided solutions through modules and components allowing collecting, processing and handling mixed data. Besides, the three approaches: Rathore et al., Krylovskiy et al.,and Panganelli et al., focus more, respectively, on the contextual processing of data and on their management when they are with huge volume. Second, the presented Smart Cities approaches don't satisfy always the security and the scalability requirements. Only interoperability is satisfied by all presented approaches. Recoverability is not supported by any retained approach in this literature review. Finally, this survey highlights the flexibility and the interesting capability of IoT to be integrated with different technologies: Cloud Computing, Big Data, Ontology, Micro-services, etc, in order to offer efficient solutions for building Smart Cities.

\section{CONCLUSION}

Smart City tries to make the best use of innovative information technology solutions to handle with urban issues related to citizens, mobility, economy, environment and resource management. In this paper, we have introduced a literature review on IoT-based Smart Cities approaches. This survey shows how IoT platforms can be considered as an efficient and practical solution to make cities smarter and more sustainable for citizens' needs. The objective of this survey is mainly; (i) to review the most interesting IoT-based Smart Cities approaches: highlights their characteristics, the challenges they raise as well as the opportunities they offer, 


\section{Internet of Things for Smart Cities: Current Issues and Research Challenges}

(ii) to summarize the essential methodologies and techniques used by these approaches for the establishment of Smart Cities and (iii) to highlight the limitations of each approach regarding other ones, through a comparative study based on a set of relevant criteria.

Future work will propose an extended version of this work allowing studying new set of efficient IoT Smart City approaches and including new criteria describing further the specifications of these approaches. Another research axis is shown interesting to be discovered also, which is quality in IoT.

\section{ACKNOWLEDGMENT}

This research was funded by the Deanship of Scientific Research at Princess Nourah bint Abdulrahman University through the Fast-track Research Funding Program.

This work has been supported by the Deanship of Scientific Research King Khalid University.

\section{REFERENCES}

1. K. Ashton, "That 'internet of things' thing in the real world, things matter more than ideas," RFID Journal. Available on: http://www.rfidjournal. com/article/print/4986, 2009.

2. European Commission, "Internet of things in 2020 road map for the future," Working Group RFID of the ETP EPOSS, Tech. Rep, http://ec.europa.eu/information documents/iotprague2009.pdf. 2009.

3. T, Lu and W. Neng, "Future internet: The internet of things," in 3rd International Conference on Advanced Computer Theory and Engineering(ICACTE), Vol. 5, pp. 376-380., 2010.

4. Cluster of European Research Projects on the Internet of Things-CERP, " Internet of Things Strategic Research Roadmap", http://www.grifsmonitoring.pdf. project.eu/data/File, 2009.

5. E. Ahmed, I.Yaqoob, A Gani, M. Imran, and M. Guizani, "Internet-of-Things-Based Smart Environments: State of the Art, Taxonomy, and Open Research Challenges", IEEE Wireless Communications, Vol 23 N 5, pp.10 - 16, 2016.

6. G. Ishkineeva, F. Ishkineeva , S. Akhmetova, "Major Approaches towards Understanding Smart Cities Concept", Asian Social Science, Vol 11, No 5, 2015.

7. V. Fernandez-Anez, and G. Velazquez-Romera, Smart Cities: Concept \& Challenges, Ascimer Project Work Package 1. Part1, Available on: https://institute.eib.org/wp-content/uploads/2017/02/2017_0131-ASCI MER-DELIVERABLE-1A-CONCEPT-CHALLENGES.pdf, 2015.

8. P. Suresh, J. Vijay Daniel, V. Parthasarathy, R.H. Aswathy, "A state of the art review on the Internet of Things (IoT) History, Technology and fields of deployment". International Conference on Science Engineering and Management Research (ICSEMR). 27-29 Nov. Chennai, India? 2014.

9. U. Gupta, "Monitoring in IOT enabled devices", Int. J. Advanced Networking and Applications, Vol 07 N 1, pp. 2622 2625, ISSN: 0975-0290, 2015.

10. R. Lea and M. Blackstock,"Smart Cities: an IoT-centric Approach", Proceedings of the 2014 International Workshop on Web Intelligence and Smart Sensing, pp. 1-2, Saint Etienne, France, 2014.

11. D. Bonino, M.T. Alizo, A. Alapetite, T. Gilbert, M. Axling, H. Udsen, J.A. Soto, and M. Spirito, "ALMANAC: Internet of Things for Smart Cities", 3rd International Conference on Future Internet of Things and Cloud, Rome, Italy, DOI: 10.1109/FiCloud.2015.32, 2015.

12. Z. Khan, S.L. Kiani and K. Soomro, "A framework for cloud-based context-aware information services for citizens in smart cities", Journal of Cloud Computing: Advances, Systems and Applications, 3. Vol 3 No 1, p.14, ISSN 2192-113X Available on: http://eprints.uwe.ac.uk/23559, 2014.

13. A. Krylovskiy, M. Jahn and E. Patti, "Designing a Smart City Internet of Things Platform with Microservice Architecture", 3rd International Conference on Future Internet of Things and Cloud, Rome, Italy, DOI: 10.1109/FiCloud.2015.55, 2016.

14. F. Paganelli, S. Turchi, and D. Giuli, "A Web of Things Framework for RESTful Applications and Its Experimentation in a Smart City", IEEE Systems Journal, Vol 10 No 4, pp. 1412 - 1423, DOI: 10.1109/JSYST.2014.2354835, 2014.

15. M.Rathore , A. Paul , A. Ahmad, and S.Rho, "Urban planning and building smart cities based on the internet of things using big data analytics", Computer Networks, Vol 101, pp. 63-80, https://doi.org/10.1016/j.comnet.2015.12.023, 2016.

16. B.Cheng, G. Solmaz, F. Cirillo, E. Kovacs, K. Terasawa, and A.Kitazawa, "FogFlow: Easy Programming of IoT Services Over Cloud and Edges for Smart Cities", IEEE INTERNET OF THINGS JOURNAL, VOL. 5, NO. 2, APRIL 2018.

17. H.Teng, Y. Liu, A. Liu , N. Xiong, Z. Cai, T. Wang and X. Liu, “A novel code data dissemination scheme for Internet of Things through mobile vehicle of smart cities", Future Generation Computer Systems, pp 351-367, 2019.

18. R. Lester, "Scalability - What it means and why it's so critical in the IoT", Article, Available on: https://www.itproportal.com/features/scalability-what-it-means-and-w hy-its-so-critical-in-the-iot/, 2017.

\section{AUTHORS PROFILE}

Omnia Saidani Neffati is an Assistant Professor at the Computer Science Department, College of Science and Arts of Sarat Abida, King Khalid University, KSA. She received her $\mathrm{PhD}$ degree in Computer Science from the University of Manouba, Tunisia. She has contributed in a number of research publications in referred journals and conferences. She is part of a number of program and organization committees in international ranked conferences. Her research interests include Information Systems, Business Processes Management, Context-awareness, Web services and Internet of Things.

Oumaima Saidani is an Assistant Professor at the Information Systems Department, College of Computer and Information Sciences, Princess Nourah bin Abdulrahman University (PNU), KSA. She received her PhD degree in Computer Science from the University Paris 1-Pantheon-Sorbonne and her Master degree in Computer Science from the University Paris9-Dauphine. She has contributed in a number of research publications in referred journals and conferences. She is part of a number of program and organization committees in international ranked conferences. Her research interests include Information Systems Engineering, Business Processes Management, Context-awareness, Web services and Internet of Things (IoT)

Dr. Devi Mani received her Ph.D degree from Anna University Chennai in the field of Computer Applications. She has been worked from Lecturer to Associate Professor since 2003 in India and abroad. Presently she is working as an Assistant Professor / Computer Science department at King Khalid University, Kingdom of Saudi Arabia. She is a reviewer for SCI indexed International Journals are "Elsevier - Computer Communications, Transactions on Services Computing". She has published more than twenty research articles in journals/conferences also she published 1 book and two Springer lecture notes. Her areas of interest in Teaching, Learning \& Research are: Wireless Communications | MANETs | Software Engineering Artificial Intelligence | Internet of Things | Machine Learning | Soft Computing: Neural Network, Fuzzy \& Optimization | Programming and Data Structures. She became a Member of ISTE since 2011. achievements, with photo that will be maximum 200-400 words.

Pooja Dixikha.G studying Electronics and Communication Engineering at Sona College of Technology, Salem - India. She has published more than ten research articles in journals/conferences and published two Springer lecture notes. She became a member of IETE since 2019. Her areas of interest in Learning \& Research are: Wireless Communications | Ethical Hacking Artificial Intelligence | Internet of Things | Machine Learning 